\title{
A la praxis por el retorno a la dialéctica (o sobre el "leninismo" de Th. W. Adorno)
}

\author{
To praxis through the return to dialectic \\ (or About Th. W. Adorno's "Leninism") \\ Marcela Vélez León \\ Institut für Philosophie - Friedrich Schiller Universität Jena \\ dmvelezleon@gmail.com
}

DOI: http://doi.org/10.15366/bp2019.21.014

Bajo Palabra. II Época. No21. Pgs: 239-252 


\section{Resumen}

El objetivo del presente artículo es analizar el alcance que sobre el desarrollo filosófico de Theodor W. Adorno pudiera haber ejercido la figura de Lenin. ¿Cabe decir que Adorno fuera "leninista"? Toda vez que las referencias a Lenin son más bien escasas en el corpus bibliográfico de Adorno, resulta cuando menos llamativo que éste le propusiera a Max Horkheimer realizar un "manifiesto estrictamente leninista" en 1956. Para profundizar en este interrogante será esencial reflexionar sobre el devenir de la noción de "praxis" a comienzos del siglo XX, especialmente en su vínculo con el pensamiento dialéctico heredado de la filosofía hegeliana.

Palabras Clave: Teoría, praxis, dialéctica, Lenin, Adorno, Hegel.

\section{Abstract}

The aim of this article is to analyse the scope that Lenin's figure could have exerted on Theodor W. Adorno's philosophical development. Could be said that Adorno was "Leninist"? Since references to Lenin are rather scarce in Adorno's bibliographic corpus, it is at least striking that Adorno proposed to Max Horkheimer to make a "strictly Leninist Manifest" in 1956. To deepen this question, it will be essential to reflect on the evolution of the notion of "praxis" at the beginning of the 20th century, especially in its link with the dialectical thought inherited from Hegelian philosophy.

Keywords: Theory, praxis, dialectics, Lenin, Adorno, Hegel. 
L a noción marxiana de "praxis" [Tätigkeit ${ }^{1}$ ha sido, sin duda alguna, objeto de sumarios debates de gran importancia para el devenir del marxismo, debates tales como el que tuvo lugar en el seno de la II Internacional a principios del siglo XX. Y es que, en función de cómo esta noción fuese interpretada, la revolución —y la lucha de clases_ habría de seguir unos cauces u otros. Así pues, la pregunta por la praxis resulta clave para comprender, no sólo la deriva de aquella Internacional, sino el devenir revolucionario en Rusia y la constelación histórica en la que aquella revolución se inserta o, dicho de otro modo: el tiempo de barbarie que denunciaran Adorno y Horkheimer en su Dialéctica de la Ilustración. Pero incluso más aún: la reflexión sobre la praxis ha de ser tomada en consideración toda vez que se quiera una profundización en la filosofía de Adorno en tanto que su formulación dialéctica está en íntima relación con aquélla.

Atendiendo a la "Introducción" de la obra cumbre de Adorno, Dialéctica Negativa, no resulta descabellado entenderla en diálogo directamente con lo escrito por Marx. Tal comienzo señala que: "la filosofía, que antaño pareció superada, sigue viva porque se dejó pasar el momento de su realización. El juicio sumario de que no ha hecho más que interpretar el mundo y mutilarse a sí misma de pura resignación ante la realidad se convierte en derrotismo de la razón, después que ha fracasado la transformación del mundo [...] Tal vez la interpretación que prometió una transición a la praxis fue insuficiente. El momento del que dependió la crítica de la teoría no puede prolongarse teóricamente. Cuando la praxis se aplaza indefinidamente deja de ser instancia crítica contra una fatua especulación para convertirse casi siempre en el pretexto bajo el que los ejecutivos estrangulan el pensamiento crítico como si fuera una pedantería; pero una praxis dinamizadora necesita de él". ${ }^{2}$

No cabe duda de que tanto la "interpretación" [Interpretation] como la "transformación del mundo" [Veränderung der Welt $]^{3}$ a las que se refiere aquí Adorno hacen

\footnotetext{
${ }^{1}$ En el sentido en el que se describe en la primera de las "Tesis sobre Feuerbach" (Cfr. Marx, K., "Tesis sobre Feuerbach”, en Marx, K. y Engels, F., Obras escogidas, vol. 1, Moscú, Ed. Progreso, 1981, p. 7)

2 Adorno, Th., Dialéctica Negativa, Madrid, Taurus, 1984, p. 11

3 Es importante atender aquí a que Adorno está utilizando el término "Interpretation" y no "Deutung”. Esta diferencia es clave porque, mientras que para Adorno la filosofía es Deutung (en oposición a la investigación [Forschung] de las ciencias particulares; véase Adorno, Th. "La actualidad de la filosofía" en Escritos filosóficos tempranos, Madrid, Akal, 2010, especialmente p. 305), la Interpretation en tanto "filosofía fallida», podríamos decir, es la que permite poner en conexión directa este fragmento con el escrito de Marx, toda vez que ambos utilizan los mismos conceptos.
} 
alusión a las referidas por Marx en la undécima de sus Tesis sobre Feuerbach, ${ }^{4}$ tesis en las que, por lo demás, se pone de manifiesto la importancia de la praxis frente al materialismo "incompleto" de Feuerbach. ${ }^{5}$ Sin embargo, como se acaba de señalar, Adorno también indica que el intento transformador - revolucionario- fracasó, por lo que se hace necesaria una reflexión — pensamiento crítico- que ponga en cuestión, precisamente, el devenir filosófico que ha llevado hasta tal fracaso (todo ello, claro está, con la vista puesta en la posibilidad de realización de la praxis). En este sentido, uno de los resultados fundamentales del análisis adorniano tendrá que ver con lo que históricamente le hubiera ocurrido al pensamiento dialéctico, eje central de la filosofía de Marx, y que supondrá el lugar de anclaje de la del propio Adorno.

Tiempo antes de que Adorno expusiera sus consideraciones sobre el devenir del marxismo, de la filosofía y, en fin, de la dialéctica, en la obra de 1966, fueron varias las ocasiones en las que, de modo concreto, el filósofo alemán bregó con estos asuntos de modo tal que podemos seguir un rastro claro desde finales de la década de los ańos treinta. ${ }^{6} \mathrm{Al}$ menos tenemos constancia de que desde 1939 Adorno y Horkheimer mantuvieron varias conversaciones ${ }^{7}$ planteándose la idea de escribir

\footnotetext{
${ }^{4}$ Aunque esta "Tesis" es bien conocida, no está de más recordar aquí las palabras de Marx: "Los filósofos no han hecho más que interpretar de diversos modos el mundo, pero de lo que se trata es de transformarlo" (Marx, K., "Tesis sobre Feuerbach", op. cit., p., 9). Es importante fijarnos en el original alemán a la hora de comprender la conexión con el escrito de Adorno: „Die Philosophen haben die Welt nur verschieden interpretiert, es kommt aber darauf an, sie zu verändern” (Marx, K., „Thesen über Feuberbach "en Marx, K., u. Engels, F., Werke, Bd.3, Berlin 1978, s. 5)

${ }^{5}$ En este sentido, es interesante recordar que, si bien Marx escribió las Tesis en 1845, su intención nunca fue publicarlas. Se trataba más bien de una serie de "notas" que, como material preparatorio, habrían de servir de base para el desarrollo de La ideología alemana, texto que, por otra parte, tampoco fue publicado en vida de sus autores y que, según su propio testimonio, habría servido como medio para esclarecer sus ideas. A pesar de ello, en 1888 Engels se encargó de la publicación de —-sólo— las Tesis (añadiendo, además, algunas modificaciones), mientras que La ideología alemana no vería la luz hasta ya entrado el siglo XX (concretamente en 1932, al menos de modo íntegro y no fragmentario como algunas versiones anteriores). Esta distancia temporal entre ambas publicaciones está a la base de que muchos de sus exégetas hayan caído en "confusiones fundamentales" en el devenir del marxismo, afectando, cómo no, a la crítica de Marx al materialismo aún "incompleto, abstracto y teoricista" de Feuerbach. Para un desarrollo en profundidad de esta cuestión, véase Candioti, M., "El carácter enigmático de las Tesis sobre Feuerbach y su secreto" en Isegoría, Revista de Filosofia Moral y Política, no 50, enero-junio, 2014, pp. 45-70, especialmente pp. 46-53.

${ }^{6}$ Es en esta década cuando, por un lado, se publicaron algunos textos hasta entonces inéditos del "joven" Marx (véase nota anterior), de modo tal que "la reflexión sobre teoría y praxis [...] para todos los rebeldes cultos de buena familia de la Alemania posterior a la Primera Guerra Mundial era indisociable del descubrimiento de un Marx anterior a la Revolución de 1848 y mediado por Lenin" (Claussen, D., Theodor W. Adorno. Uno de los últimos genios, Universitàt de Valencia, 2006, p. 252) y, por otro lado, la colaboración entre Adorno y Horkheimer empezó a ser más seria y continuada. Tal colaboración habría de suponer que Adorno superase las "enfermedades intelectuales de la infancia" (Ibíd., p. 258) en lo que a su pensamiento político se refiere.

${ }^{7}$ Hay constancia de que por lo menos en tres ocasiones la idea de redactar un manifiesto fue ampliamente discutida por Adorno y Horkheimer:
} 
un manifiesto al estilo — según el propio Horkheimer- del Manifiesto Comunista ${ }^{8}$ y a través del cual proponer una especie de "programa" para una nueva forma de práctica. ${ }^{9}$ Unos años más tarde, en 1956, será el propio Adorno quien vuelva a referirse a dicho manifiesto, pero ahora señalándolo como un "manifiesto estrictamente leninista", afirmación que no deja de ser sorprendente teniendo en cuenta las pocas referencias directas a Lenin que se encuentran en el corpus bibliográfico adorniano. ${ }^{10}$ De ahí que la pregunta que necesariamente se plantea sea: ¿qué significa este "retorno" a Lenin?

Lo que en este punto se quiere argumentar es que, el hecho de que Adorno haya propuesto ese retorno a Lenin a la hora de pensar sobre cómo articular teóricamente la praxis posible (y concretarlo en un manifiesto), puede ser entendido como un retorno a Hegel, o dicho más concretamente, una recuperación de la dialéctica. Que Adorno tuviera a Lenin en mente no significaría, entonces, una "desviación del contenido sistemático" de su filosofía, ${ }^{11}$ sino que, a mi juicio, se trataría más bien de una primera constatación de lo que constituirá el punto neurálgico de sus reflexiones sobre la relación (dialéctica) entre teoría y praxis — sobre todo después de la

a) La primera de ellas habría tenido lugar durante una serie de encuentros en el otońo de 1939 y habría sido la menos "problemática" ya que aún concebían el manifiesto como una posibilidad real — hasta el punto de establecer los "catorce puntos centrales" que se habrían de abordar en él一. Estas reflexiones han sido recogidas por Gunzelin Schmid Noerr, editor de las Max Horkheimer Gesammelte Schriften, como „Diskussionen über Sprache und Erkenntnis, Naturbeherrschung am Menschen, politische Aspekte des Marxismus “; en Bd. 12, S. Fischer, Frankfurt am Main, 1985, p. 493 y ss.

b) Por otro lado, ya en 1945, esto es, tras el cambio radical que había supuesto la Segunda Guerra Mundial, Adorno y Horkheimer vuelven a explorar la idea del manifiesto, pero exponiendo sus dudas acerca de la posibilidad de la "teoría" tras los sucesos bélicos. Estas conversaciones, inéditas y sin título, pueden encontrarse en el texto conservado en el Theodor W. Adorno Archiv Ts. 52528 - 52533

c) Y finalmente en 1956, tiempo en el que, corroborando la penosa situación en la que se encontraba la teoría y declarándose firmes defensores del comunismo más allá del partido, vuelven a rondar la idea del manifiesto, en este caso, y según Adorno, un "manifiesto leninista estricto". Las conversaciones correspondientes a este periodo, cuyas notas debemos agradecer a Gretel Adorno, fueron recogidas bajo el título „Diskussion über Theorie und Praxis "en Horkheimer Gesammelte Schriften, Bd. 19, her. von G. Schmid Noerr; mit Beitr. von Jan Baars... [et al.], S. Fischer, Frankfurt am Main, 1996. Más recientemente han sido publicadas en la traducción al inglés de Rodney Livingstone bajo el título Towards a New Manifesto (Verso, 2011).

Para un desarrollo en profundidad de esta cuestión, véase Braunstein, D., Adornos Kritik der politischen Ökonomie, Bielefeld, Transkript Verlag, 2015

8 Concretamente, Horkheimer seńala que: „Also wie im Kommunistischen Manifest. Die Sätze stellen Erfahrungen dar. Wir sollten uns einmal an einem Text versuchen, der solche Tendenzen hat..." (Horkheimer, M. y Adorno, Th., „Diskussionen über Sprache...“, op, cit., p. 509). [“Como en el Manifiesto Comunista. Las frases representan experiencias. Deberíamos probar con un texto que tenga esas tendencias [...]” (trad. M.V.)]

9 Cfr. Ibíd., pp. 493 y ss.; También Horkheimer M. y Adorno, Th., “Diskussion über Theorie...”, op. cit. pp. 19 y ss.

${ }_{10}$ Aunque en la correspondencia de Adorno, sobre todo con Horkheimer, sí se encuentran varias alusiones a Lenin, no así en las obras publicadas por él.

${ }^{11}$ Cfr. Brumlik, M., "Adorno, Lenin und das Schnabeltier" en TAZ, 3.7.2012 disponible en http://www.taz. de/!5089939/ [trad. M. V.]) 
verificación del fracaso de la praxis revolucionaria y la integración del proletariado en el sistema- y que se concretará cada vez más en sus escritos posteriores.

En sus "Reflexiones sobre la teoría de clases", escritas en 1942 y que sentarían las bases de las consideraciones económicas que luego habrían de aparecer en la Dialéctica de la Ilustración, ${ }^{12}$ Adorno afirmaba que "Marx murió mientras desarrollaba la teoría de clases, y el movimiento obrero la abandonó tal como aquel la dejó". ${ }^{13}$ Lo que ello viene a decir es que la teoría de clases perdió con el marxismo el vigor que tenía con Marx, perdió su capacidad crítica ${ }^{14}$ hasta tal punto que terminó por convertirse en "segunda naturaleza" ${ }^{15}$. Y ello no sólo ocurrió con la teoría de clases sino con la filosofía de Marx en general, tal como lo ponían de relieve los hechos sucedidos en la Rusia del siglo XX. De ahí que en 1950 Adorno y Horkheimer considerasen que: "el espíritu de la crítica no puede detenerse ante aquella Rusia que

12 Tras haber redactado sus "Reflexiones" (Adorno, Th., "Reflexiones sobre la teoría de clases" en Escritos sociológi$\cos$ I, Madrid, Akal, 2004), Adorno escribió a sus padres (Cfr. Carta de Adorno a sus padres del 1 de septiembre de 1942 en Adorno, Th., Briefe und Briefwechsel - Band 5: Briefe an die Eltern. 1939-1951, Frankfurt am Main, Suhrkamp, 2003, Bd. 5 p. 160) indicándoles que había concebido una "nueva teoría económica" que actualizaba la doctrina de Marx. También escribió a Horkheimer unos días después señalándole que se había ocupado del esquema de la cultura de masas que podría aparecer en la Dialéctica de la Ilustración que pensaban escribir: "Por otro lado, me ocupé del aspecto teórico y escribí nueve «reflexiones sobre la teoría de clases», en parte formulaciones de cosas comunes con respecto a la teoría de los Rackets, en parte también otras completamente nuevas. Este manuscrito está construido de tal manera que puede ser fácilmente disuelto y transferido al producto final en lugares completamente diferentes, dependiendo de las necesidades. También hay una sección sobre empobrecimiento y otra sobre sociología formal". Como señala Braunstein, este escrito de Adorno de 1942 representa el abandono de una reflexión puramente económica a una ampliada y enmarcada dentro del conjunto completo de la Dialéctica de la Ilustración en la que ni siquiera aparecerán alusiones explícitas a Marx. (Cfr. Braunstein, D., op. cit., p. 169)

13 Adorno, Th., "Reflexiones sobre la teoría de clases", op. cit. p. 354

${ }^{14}$ No está de más recordar en este punto que Marx, para Adorno, puede ser considerado como el primer pensador de Teoría Crítica: "In a 1962 seminar, Adorno was quite explicit on his relationship to Marx he identified him as the first great theoretician of critical theory and stressed the importance of the theory of fetishism for understanding valorization as an abstract conceptualization of social relations", Vincent, J. M., "Adorno and Marx" en Bidet, J., \& Kouvelakis, S., (Eds.) Critical Companion to Contemporary Marxism, Leiden, Brill, 2008, p. 495

15 La idea de "segunda naturaleza" es tomada por Adorno de la filosofía de Lukács. Es en su descripción del mundo enajenado o "mundo de la convención" — que se contrapone al "mundo lleno de sentido"—, donde Lukács incorpora, heredándola de Hegel, esta categoría: "el mundo de la convención [es] un mundo dentro de cuyos inmensos poderes se hallan todas las cosas, excepto los recovecos más profundos del alma; un mundo presente en todo lugar, en una multiplicidad de formas demasiado complejas para ser comprendidas. Sus estrictas leyes, tanto en el devenir como en el ser, son necesariamente evidentes para el sujeto cognoscente, pero a pesar de su regularidad, es un mundo que no se ofrece como sentido para el sujeto que busca fines ni como sustancia, en inmediatez sensible, para el sujeto activo. Se trata de una segunda naturaleza y, como la primera, es determinable únicamente en tanto encarnación de necesidades reconocidas pero extrañas al sentido y, por lo tanto, resulta incomprensible e inaprensible en su verdadera sustancia" (Lukács, G., Teoría de la novela, Buenos Aires, Ediciones Godot, 2010, p. 57). Para una consideración en mayor profundidad de la lectura adorniana de esta "segunda naturaleza", véase Adorno, Th., "La idea de historia natural" en Escritos Filosóficos tempranos, Madrid, Akal, 2010, pp. 324-333 y Adorno, Th., Zur Lehre von der Geschichte und von der Freiheit (1965/65), Nachgelassenen Schriften, Bd. 13, hrsg. Von Rolf Tiedemann (hrsg. Vom Theodor W. Adorno Archiv), Frankfurt am Main, Shurkamp, 1993, pp. 173-186. 
de hecho encarnó aquella esperanza del fin de la guerra y que hoy degrada a mera fraseología [...] la esencia del pensamiento crítico, en el que siempre nos mantendremos, consiste en no someterse a ninguna autoridad y preservar el elemento de la experiencia viva y la libertad de crítica frente a las ideas más influyentes. Pues ningún pensamiento está a salvo de la obcecación cuando, arrancado de aquella experiencia viva, se instala como un ídolo. Esto es lo que hoy le sucede a la concepción marxista. Cuanto más se repiten maquinalmente sus principios, tanto más probable es la inversión de su sentido. Cuando se hace de la teoría de Marx un sistema positivo, una fórmula universal, el resultado es un empobrecimiento indecible de todo conocimiento y toda praxis, y al cabo una imagen engañosa de la realidad". ${ }^{16}$

En tal desfiguración tuvo mucho que ver el devenir mismo de la dialéctica, la cual, tomada como instrumento, se convirtió en arma de dominio en nombre de la última y definitiva revolución que estaba por venir, la Revolución rusa. Y es que la dialéctica bien puede ser "método perenne de crítica" como "medio de dominación" en tanto que "su verdad o falsedad no está en el método en sí, sino en su intención dentro del proceso histórico" ${ }^{17} \mathrm{o}$, dicho de otro modo: la dialéctica no es un instrumento que se pueda invocar para conducir la tendencia histórica a los fines debidos o esperados según tal o cual teoría; a la dialéctica no hay que usarla, sino que hay que perderse en ella y sólo así, sumergido en su movimiento, el pensamiento puede aprehender los momentos de la totalidad sin caer en la falsa disyuntiva que bascula entre "lo uno o lo otro"; ${ }^{18}$ sólo así, en definitiva, el pensamiento puede ser libre en su resistencia, puede ser crítico.

Ahora bien, ¿̇ómo pudo ocurrir tal conversión de la dialéctica en dogma? La discusión entre reformistas y revolucionarios de la Segunda Internacional a principios del siglo XX llevó a que la dialéctica fuera "redescubierta" por los "responsables de la teoría" para salvar el concepto de clase que estaba siendo puesto en cuestión. Sin embargo, en ese giro la propia teoría quedó atrofiada y, en su impotencia, dejó paso a una praxis escindida de la teoría que no hacía más que incrementar, precisamente, tal impotencia de la teoría y que quedaba demostrada en la fetichización de aquellos elementos que habrían de corresponder a una praxis verdadera tales como la espontaneidad, ${ }^{19}$ convirtiéndola en su opuesto, la planificación. Por ello entiende Adorno

\footnotetext{
16 Adorno, Th., "La URRS y la paz”, en Miscelánea I, Madrid, Akal, 2015, p. 395

17 Adorno, Th., Minima Moralia, Madrid, Akal, 2004, p. 254

18 "Habría que considerar bajo este aspecto a la dialéctica como intento de escapar al «o lo uno o lo otro". Ella es el esfuerzo por salvar la determinidad y la consecuencia de la teoría sin entregarlas al delirio” (Ibíd., p. 269)

19 "El paso a la praxis sin teoría es motivado por la impotencia objetiva de la teoría y multiplica esta impotencia mediante el aislamiento y la fetichización del momento subjetivo del movimiento histórico, de la espontaneidad. Su deformación es una reacción al mundo administrado" (Adorno, Th., "Notas marginales sobre teoría y praxis" en "Epilegómenos dialécticos" en Crítica de la cultura y la sociedad II, Madrid, Akal, 2009, p. 682). La
} 
que "las pseudorrealidades de algunos movimientos prácticos de masas del siglo $\mathrm{XX}$, que se han convertido en una realidad sangrienta y empero están eclipsadas por lo que no es completamente real, por lo demencial, nacieron cuando se pregunto por la praxis", ${ }^{20}$ es decir, cuando alguien preguntó: ¿Qué hacer?

Fue en 1902 cuando Lenin abrió políticamente el siglo precisamente con esa pregunta. Para comprender su vínculo con la deriva de la dialéctica recordemos brevemente que en 1914, acompañando al estallido de la Primera Guerra Mundial, se producía también la otra gran debacle a la que hacíamos alusión más arriba: el colapso de aquella Segunda Internacional. Además de la oposición ideológica que venía dándose entre sus filas y que enfrentaba a reformistas y revolucionarios, el estallido de la "Gran Guerra" supuso su fractura definitiva, de tal suerte que, mientras la mayoría de sus miembros pasaron a ser defensores de aquella "guerra imperialista", otros pocos, como Lenin, mantuvieron una firme oposición a ésta en pos de la verdadera lucha: la lucha de clases. ${ }^{21}$ El propio Lenin narra lo que él considera una gran traición: "lo más penoso para un socialista no son los horrores de la guerra siempre estamos en favor de la "santa guerra di tutti gli opressi per la conquista delle loro patrie!»-, sino los horrores de la traición de los dirigentes del socialismo de nuestro tiempo, los horrores de la bancarrota de la II Internacional". ${ }^{22}$

Ante esta situación, la respuesta de Lenin, antes de proceder a análisis apresurados o a tomar decisiones políticas, consistió en reflexionar sobre los fundamentos teóricos del marxismo volviendo, para ello, a la filosofía hegeliana y en concreto a la Lógica. La lectura de las obras de Hegel supuso sin duda un hito fundamental

insistencia de Adorno en la espontaneidad como categoría revolucionaria (véase, por ejemplo, la consideración de la espontaneidad en la Revolución francesa en "La idea de historia natural") me lleva a sostener un doble argumento: en primer lugar, la apreciación de Adorno de la filosofía política de Rosa Luxemburg, defendiendo la espontaneidad y apostando por una dialéctica entre espontaneidad y organización. Y es que Luxemburg tuvo una visión realmente aguda sobre los problemas que habrían de acuciar a la revolución bolchevique, como pondría de relieve su polémica con Lenin por, entre otras cosas, el anti espontaneísmo que aquél hubiera defendido en su ¿Qué hacer? Esto me lleva al segundo argumento y es que: si Adorno se aproximaba más al pensamiento de Rosa de Luxemburgo que al de Lenin, ello permite interpretar con más fuerza que las críticas a los funcionarios del Diamat que desarrollaremos a lo largo de este artículo implican también al propio Lenin.

${ }^{20}$ Adorno, Th., "Notas marginales sobre teoría y praxis", op. cit., p. 676

${ }^{21}$ En este sentido, y aunque Adorno no se refiera directamente a Lenin, no cabe duda de que piensa en él cuando, en sus "Reflexiones sobre la teoría de clases" analiza la conversión de dicha teoría en "segunda naturaleza" y señala que "sólo los reformistas debatieron sobre la cuestión de las clases para, con la negación de la lucha, de la apreciación estadística de las capas medias y el elogio del progreso transformador, encubrir la traición que empieza a apuntar. La negación falaz de las clases movió a los defensores responsables de la teoría [véase: Lenin, entre otros, M.V.] a proteger el concepto de clase mismo en tanto que pieza didáctica, sin seguir impulsándolo. Con ello la teoría se ha descubierto como cómplice de la corrupción de la praxis" (Adorno, Th., "Reflexiones sobre la teoría de clases” op. cit. p. 354-35)

22 Lenin, V. I., "La guerra europea y el socialismo internacional” en Obras completas, Tomo XXII, Akal, Madrid, 1977 , p. 90 
para el desarrollo teórico del político ruso. Si se comparan sus escritos anteriores y posteriores a 1914 cabe rastrear diferencias en sus posiciones teóricas que muestran el cambio que la Lógica produjo en él. En este sentido, tengamos en consideración que en 1909 vio la luz Materialismo y empirocriticismo, obra en la que había trabajado Lenin a lo largo de 1908 y en la que se destacan fundamentalmente dos aspectos interrelacionados entre sí, a saber: a) la importancia de la llamada "teoría del reflejo" y b) el rechazo radical del idealismo, rechazo que, tras la lectura de la Lógica, se desplazará hacia el "materialismo vulgar" — conceptualización acuñada, precisamente, a raíz de esta lectura- y se suavizará de manera tal que cabe decir que se irá produciendo una "apropiación critica de la dialéctica idealista de Hegel para conectarla con el materialismo marxista". ${ }^{23}$ En definitiva, Lenin superará la oposición simplista anteriormente sostenida por Engels entre materialismo e idealismo viéndola ahora, en línea con Marx, como una relación dialéctica.

Lenin pretendía rescatar materialistamente el lado "activo-subjetivo" del idealismo, esto es: la no superioridad del pensamiento por encima de la realidad. Esta defensa, que había desarrollado anti idealistamente en 1909, será clave en el análisis de la Lógica. A lo largo de las notas que el pensador ruso va tomando de su lectura, se aprecia cómo la teoría del reflejo va reconfigurándose. Al comienzo Lenin define el reflejo como una vertiente de la realidad coextensiva con la dialéctica; o, dicho con otras palabras: el desarrollo material del mundo tiene un reflejo que se manifiesta dialécticamente. Todavía en sus notas del final de la "Doctrina de la esencia" podemos ver cómo Lenin sigue anclado a esta visión cuando señala, según sus palabras, a la dialéctica como "reflejo correcto del eterno desarrollo del mundo". ${ }^{24}$ Sin embargo, al comienzo de la "Doctrina del concepto" Lenin anota al margen: "la conciencia del hombre no sólo refleja el mundo objetivo, sino que lo crea". ${ }^{25}$ Y aquí ya es claro: Lenin había tomado conciencia de la necesaria inmanencia de las categorías hegelianas y, con ello, dio el primer paso para la superación del dualismo engeliano entre materialismo e idealismo, hasta que, finalmente, concebirá al reflejo, esto es, la actividad del pensamiento formando conceptos abstractos, no ya como una duplicidad sino como el proceso que revela propiamente la objetividad del conocimiento subjetivo. El reflejo no aparece entonces como la "externalidad de la materia de los objetos que internamente se presentan a la conciencia”, es decir: como la irreductibilidad de la naturaleza al espíritu; más bien se ha

\footnotetext{
23 Anderson, K., "El redescubrimiento y la persistencia de la dialéctica en la filosofía y la política mundiales" en Budgen, S., Kouvelakis, S., Zizek, S., Lenin reactivado. Hacia una politica de la verdad, Madrid, Akal, 2010, p. 127

${ }^{24}$ Lenin, V. I., "Resumen del libro de Hegel Ciencia de la Lógica" en Obras completas, Tomo XLII Cuadernos Filosóficos, Madrid, Akal, 1997, p. 107

25 Ibíd., p. 200
} 
dado la muy famosa "inversión materialista de Hegel”26. Ésta no consiste "en afirmar la primacía del ser sobre el pensamiento, sino en entender la actividad subjetiva expuesta en la «lógica del concepto» como el «reflejo» idealista y por ello invertido de la práctica revolucionaria, que transforma la realidad revelando así el resultado de la intervención del sujeto". ${ }^{27}$ A partir de aquí no cabe duda del alejamiento definitivo de Lenin respecto a Engels, Plejanov y el marxismo hasta entonces dominante, alejamiento que a la vez supone la inauguración de una nueva doctrina que considerará que el motor de la revolución no es otro que la propia dialéctica. La atención que prestase Lenin a la dialéctica y que aparece fielmente reflejado en sus Cuadernos filosóficos de 1914 constituye el primer paso decisivo de su estrategia para superar la crisis de liderazgo de la clase obrera que se había manifestado ya al comienzo de la Primera Guerra Mundial. En definitiva, podemos decir que la revisión (o inversión) materialista de Hegel por parte de Lenin le lleva desde la Lógica hasta la dialéctica, gesto con el que, a su vez, reintroduce de pleno a Hegel en la filosofía política del siglo XX. Ésta, la dialéctica, se convertiría desde entonces en su interés principal a partir del cual pensará la revolución como su correlato, ${ }^{28}$ abriendo así el camino para el Diamat soviético que habría de confirmar, para Adorno, la máxima de que toda teoría es susceptible de cosificarse. ${ }^{29} \mathrm{Y}$ es que "el pensamiento dialéctico es el ensayo de romper el carácter impositivo de la lógica con los medios de ésta. Pero, al tener que servirse de estos medios, a cada momento corre el peligro de sucumbir él mismo a ese carácter impositivo: la astucia de la razón es capaz de imponerse aún a la propia dialéctica”. ${ }^{30}$

${ }^{26}$ Cfr. Kouvelakis, S., "Lenin como lector de Hegel. Hipótesis para una lectura de los Cuadernos de Lenin sobre La ciencia de la lógica” en Budgen, S., Kouvelakis, S., Zizek, S., op. cit., p. 180

27 Ibíd.

${ }^{28}$ No pensemos que el interés teórico de Lenin se detuvo en la breve reflexión que constituye su "Sobre la dialéctica" ya que la transformación radical que el estudio de la filosofía hegeliana produjo en aquel se mantuvo presente hasta en sus últimos escritos. Así podemos verlo en su obra de 1922, Sobre la significación del marxismo militante, en la que hacía un llamamiento a construir algo así como una "Sociedad de amigos materialistas de la dialéctica hegeliana”. En definitiva, la lectura crítica de Hegel ayudó precisamente a Lenin a liberarse de la ortodoxia anti dialéctica de la II Internacional. Gracias a ello, Lenin recorrerá el camino que lo llevará desde aquella biblioteca de Berna a la estación finlandesa de Petrogrado en la que, cuatro años después, liderará, guiado por la dialéctica, la esperada revolución, la Revolución de Octubre.

29 Cfr. Adorno, Th., Minima Moralia, op. cit., p. 268-269. También en sus Tres estudios sobre Hegel, Adorno advierte de los peligros de la utilización de la dialéctica: "Los elementos más reaccionarios de Hegel, no los liberal-progresistas, prepararon el terreno a la posterior crítica socialista del utopismo abstracto, aunque para luego proporcionar también, en la historia del socialismo, pretextos para renovadas represiones. El ejemplo más drástico es la difamación, actualmente habitual en la zona oriental, de todo pensamiento que se eleve sobre la testaruda inmediatez que allí se fomenta bajo el concepto de praxis. Sólo que no debería echarse la culpa a Hegel cuando se utilizan sus motivos para disimular ideológicamente el horror ininterrumpido. La verdad dialéctica se expone a semejante utilización: su naturaleza es frágil“ (Adorno, Th., Tres estudios sobre Hegel, Madrid, Akal, 2012, p. 294

30 Adorno, Th., Minima Moralia, op. cit., p. 98 
Cabe pensar que es a este "renacimiento" del hegelianismo en el siglo XX al que se refiere Adorno en el primero de sus Tres escritos sobre Hegel ("Aspectos de la filosofía hegeliana") que escribiera con ocasión de la celebración del 125 aniversario del nacimiento de aquél y en donde Adorno vuelve a Hegel para oponerse críticamente a tal hegelianismo. Sus referencias críticas contra "los administradores de la dialéctica en su versión materialista, ese magro pensamiento oficial del bloque oriental, [que] la han degradado a la irreflexiva teoría del reflejo [de modo que] la dialéctica, limpia así del fermento crítico, se presta al dogmatismo", apuntan a que Adorno no pasa por alto la influencia de Lenin en el hegelianismo posterior. Y es que, como se ha venido señalando, la dialéctica no se utiliza, no se aplica, en definitiva: no es otro instrumento más. Por eso Adorno continúa afirmando tajantemente que: "si despojamos a la filosofía hegeliana de la rigurosidad de su construcción, en verdad deja de ser algo así como una filosofía, y entonces pasa a ser meramente una acumulación rapsódica de una serie de intelecciones materiales más o menos significativas [...]. En otras palabras, sin tener un concepto de dialéctica, estricto y correctamente desarrollado [...] se estaría renunciando en realidad a esa fuerza única con la que le fueron concedidas a Hegel sus intelecciones pues creo que [...] él le debe la posibilidad de comprender la realidad tal como la comprendió [...] solo al principio dialéctico y que sin ese principio dialéctico en su rigurosidad también aquello que ha quedado de Hegel en la conciencia general, esto es, la idea del desarrollo, de la dinámica como la categoría elevada por encima de todos los otros conceptos, debería perderse necesariamente, debería convertirse en una constatación contingente". ${ }^{31}$

Ahora bien, que tal crítica fuese dirigida contra Lenin en particular o contra el leninismo posterior no queda del todo claro ya que, si bien Adorno nunca hace referencia explícita a Lenin cuando critica al Diamat, sí insiste en que "no hay que despachar apresuradamente el fenómeno idealista hegeliano" 32 ya que en el idealismo se halla, precisamente, la fuerza que permite entender que los conceptos no son entidades muertas, como podría pretender un pensamiento científico. ${ }^{33} \mathrm{El}$ hecho de que el idealismo, en sus palabras, refleje la "exigencia del espíritu de no manejar los conceptos como si fuesen fichas de juego" ${ }^{34}$ pone de manifiesto que el materialismo leninista, desarrollado bajo la etiqueta de Diamat, al despreciar al idealismo hizo lo que precisamente denunciaba Adorno: mitologizar los conceptos, siendo el

\footnotetext{
${ }^{31}$ Adorno, Th., Introducción a la dialéctica (1958), Buenos Aires, Eterna Cadencia, 2013, pp. 131-132

32 Adorno, Th., Tres estudios sobre Hegel, op. cit., p. 282

${ }_{33}$ Recordemos que Lenin consideraba al idealismo filosófico como "un camino hacia el oscurantismo clerical" Cfr. Lenin, V. I., "Sobre el problema de la dialéctica", en Obras completas, Tomo XLII, op. cit. p. 333

${ }^{34}$ Adorno, Th., Tres estudios sobre Hegel, op. cit., p. 282
} 
principal, desde de Lenin, el de "revolución", porque, qué duda cabe, Lenin siempre pensó a la dialéctica y a la revolución juntas. ${ }^{35}$

De tal importancia para el desarrollo del conjunto filosófico de Adorno es esta cuestión que, como se ha querido mostrar, el comienzo de la Dialéctica Negativa puede leerse como una denuncia sibilina —en los propios términos marxianosde la conversión de la dialéctica en dogma. En este sentido, que fuera Lenin o los "funcionarios" del Diamat que le siguieron quienes "depravaran" a la teoría no tiene mayor relevancia ante el hecho central, recuérdese: el fracaso en la "transformación del mundo". Sin embargo, que la filosofía aún pueda realizarse abre la puerta a la posibilidad de una praxis dinamizadora, una praxis "verdaderamente subversiva" que, eso sí, no puede ser ya la praxis fetichizada y escindida de lo teórico que se convirtió en fuerza del dominio, sino que una praxis verdadera ha de contar con la no-identidad, con la diferencia, es decir, ha de estar en íntima relación — dialécti$\mathrm{ca}$ - con la teoría que evita, precisamente, que aquélla se convierta en dogma. ${ }^{36} \mathrm{He}$ aquí, si cabe, el sentido del posible leninismo de Adorno.

35 En su escrito de 1914 sobre Karl Marx, Lenin señala que uno de los aportes más importantes que hicieran Marx y Engels con su Manifiesto Comunista fue la recuperación de la dialéctica entendida como "la doctrina más completa y profunda acerca del desarrollo [de] la teoría de la lucha de clases y de la histórica misión universal del proletariado, creador de la nueva sociedad, la sociedad comunista" (Lenin, V. I., "Karl Marx. Breve esbozo biográfico con una exposición del marxismo” en Obras completas, Tomo XXII, op. Cit., p. 140). También en sus propias reflexiones sobre la dialéctica la considera como una "ley del conocimiento de la lucha de clases" gracias a la cual, se conseguirán los objetivos revolucionarios. (Cfr. Lenin, V. I., "Sobre el problema de la dialéctica", op. cit. p. 329)

${ }^{36}$ La idea de que la filosofía — dialéctica - puede realizarse más allá del marxismo ortodoxo y, con ello, que el pensamiento sobre la praxis revolucionaria ha de ser necesariamente otro, se expone también en la respuesta que diera Adorno al “¿Para qué aún filosofía?”: "Que en Europa oriental se presente al "materialismo dialéctico» como filosofía marxista, como si fuera compatible sin más con la teoría de Marx, indica que el marxismo se ha convertido en un dogma estático, insensible a su propio contenido, en una ideología, como ellos mismos dirían. Hoy sólo se puede filosofar habiendo negado la tesis marxista de que la reflexión está superada. Esta tesis pensó la posibilidad de la transformación del mundo como algo que está presente aquí y ahora. Sólo la terquedad podría suponer hoy esta posibilidad igual que en tiempos de Marx" (Adorno, Th., "Para qué aún filosofía", en Crítica de la cultura y la sociedad II, op. cit., p. 410) 


\section{ReferenCias Bibliográficas}

Adorno, Th., Escritos filosóficos tempranos, Madrid, Akal, 2010

- Escritos sociológicos I, Madrid, Akal, 2004

- Zur Lehre von der Geschichte und von der Freiheit (1965/65), Nachgelassenen Schriften, Bd. 13, hrsg. Von Rolf Tiedemann (hrsg. Vom Theodor W. Adorno Archiv), Frankfurt am Main, Shurkamp, 1993

- Miscelánea I, Madrid, Akal, 2015

- Minima Moralia, Madrid, Akal, 2004

- Crítica de la cultura y la sociedad II, Madrid, Akal, 2009

- Tres estudios sobre Hegel, Madrid, Akal, 2012

- Introducción a la dialéctica (1958), Buenos Aires, Eterna Cadencia, 2013

- Dialéctica Negativa, Madrid, Taurus, 1984

- Briefe und Briefwechsel - Band 5: Briefe an die Eltern. 1939-1951, Frankfurt am Main, Suhrkamp, 2003

Bidet, J., \& Kouvelakis, S., (Eds.) Critical Companion to Contemporary Marxism, Leiden, Brill, 2008

Braunstein, D., Adornos Kritik der politischen Ökonomie, Bielefeld, Transkript Verlag, 2015, https://doi.org/10.14361/9783839434437

Brumlik, M., "Adorno, Lenin und das Schnabeltier" en TAZ, 3.7.2012 disponible en http://www.taz.de/!5089939/

Budgen, S., Kouvelakis, S., \& Zizek, S., Lenin reactivado. Hacia una politica de la verdad, Madrid, Akal, 2010

Candioti, M., "El carácter enigmático de las Tesis sobre Feuerbach y su secreto" en Isegoría, Revista de Filosofía Moral y Política, no 50, enero-junio, 2014, pp. 45-70,

Claussen, D., Theodor W. Adorno. Uno de los últimos genios, Universitàt de Valencia, 2006

Horkheimer, M., y Adorno, Th., Towards a New Manifesto, Londres, Verso, 2011 
Horkheimer, M., Gesammelte Schriften, Bd. 12, Frankfurt am Main, S. Fischer, 1985

- Gesammelte Schriften, Bd. 19, Frankfurt am Main, S. Fischer, 1996

Lenin, V. I., Obras completas, Tomo XXII, Madrid, Akal, 1977

- Obras completas, Tomo XLII Cuadernos Filosóficos, Madrid, Akal, 1997

Lukács, G., Teoría de la novela, Buenos Aires, Ediciones Godot, 2010,

Marx, K., y Engels, F., Obras escogidas, vol. 1, Moscú, Ed. Progreso, 1981

- Werke, Bd.3, Berlin, 1978

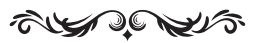

DOI: http://doi.org/10.15366/bp2019.21.014

Bajo Palabra. II Época. No21. Pgs: 239-252 